\title{
А.А. Пронин
}

\section{ИНТЕРТЕКСТУАЛЬНОСТЬ «КАК ПРИЕМ» И «ПЕРЕКЛИЧКА ТЕКСТОВ» В ДОКУМЕНТАЛЬНЫХ ФИЛЬМАХ О М. БУЛГАКОВЕ}

\begin{abstract}
В статье рассматривается использование интертекстуальных связей в качестве художественного приема создания биографического нарратива в современной отечественной теледокументалистике. Основным сюжетообразующим мотивом анализируемого ряда фильмов о М. Булгакове и его произведениях представляется «перекличка» текста литературного произведения и «текста жизни» писателя: на уровне образов, действия, топоса и смыслов. Сравнение обнаруживает разнообразие способов визуализации интертекстуальных связей, их зависимость от авторской интенции и нарративных стратегий.

Ключевые слова: документальный фильм, сюжет, мотив, интертекст, нарратив, автор.
\end{abstract}

В современной отечественной документалистике так называемые «писательские фильмы» занимают особое место - очевидно, в силу сохраняющегося до сих пор «массового беллетристического сознания» [1]. К данной категории относятся как традиционные биографические фильмы о писателях, так и фильмы, посвященные созданию конкретного художественного феномена, литературной и общественно-исторической «судьбе книги». И если для первой группы фильмов характерна универсальность (объектом внимания может стать писатель любой эпохи и взглядов), то для второй - избирательность, поскольку авторов интересуют преимущественно запрещенные или «потаенные» книги, не опубликованные в свое время по решению цензуры или по воле самого писателя, оставившего рукопись «в столе». Фильмы о литературных произведениях с «трудной судьбой» стали объектом анализа в данной статье.

Как известно, больше всего подобного рода историй в литературе советского периода, поэтому естественно, что на телеэкран выходят в основном писательские драмы именно того времени. К их числу относятся как фильмы отечественного производства, например «Загадки "Мастера и Маргариты"» (2005, авторы В. Лисовский, В. Хомич, Ю. Проскурня-Завьялова), «Рукописи не горят» (2008, автор С. Головецкий, 4 серии), «Василий Гроссман. Я понял, что я умер» (2014, автор Е. Якович, А. Шишов), так и зарубежные, в частности «Тайный путь «Доктора Живаго» (2003, Канада, автор Г. Хофман), «"Архипелаг ГУЛАГ": тайная история» (2008, Франция, авторы Ж. Крепу, Н. Милетич) и др.

Разумеется, в каждом конкретном фильме свой оригинальный сюжет, однако, на наш взгляд, важнейшими сюжетообразующими мотивами для большинства из них являются два: либо собственно приключения, а точнее, злоключения текста, ставшего впоследствии знаменитым, либо «перекличка» художественного текста и текста жизни его автора. Первый, по означенным выше причинам, реализуется в достаточно ограниченном круге фильмов, в частности в канадском и французском фильмах о романах Б. Пастернака и 
А. Солженицына, а также в отечественной картине «Василий Гроссман. Я понял, что я умер», где драматичная история романа «Жизнь и судьба» является главной сюжетной линией (арест рукописи, тайное хранение, переправка за границу и т.д.). Авторам фильма было важно рассказать не столько о самом романе, его содержании и художественных особенностях, сколько о его злоключениях, поэтому свидетельства непосредственных участников событий становятся основой экранного нарратива о судьбе романа, а по объему цитирования текст «Жизни и судьбы» заметно уступает текстам нехудожественным - письмам, дневникам, публицистике [2].

Рамки второй группы - и хронологически, и географически, и по персоналиям - значительно шире, поскольку в той или иной мере «перекличку» художественного текста и «текста жизни» можно обнаружить во многих литературных произведениях. И презентация такой «переклички» в документальном фильме, осознанное использование ее в качестве основного сюжетообразующего мотива является, на наш взгляд, реализацией творческого желания автора «дать», по выражению В.Б. Шкловского, «ощущение вещи, как видения, а не как узнавания» [3. С. 62]. Именно в таком, философскоэстетическом смысле, сближающем качественную документалистику с художественным творчеством, мы используем концепт «интертекстуальность как прием» - подобно тому, как русские формалисты говорили об «искусстве как приеме», как «способе пережить деланье вещи». «Деланье» фильма о книге и ее создателе как киновещи предполагает способность к сопряжению разнообразных текстов, к выявлению их неявных взаимосвязей, а также умение ярко представить эти связи в диегезисе фильма. Это и есть общий для данной тематической группы фильмов «прием», способ придать документалистике свойства художественной интерпретации. В то же время существует «интертекстуальность литературного произведения», означающая, в современном понимании, широкий круг взаимосвязей данного художественного текста с другими текстами, с культурной средой и миром повседневности [4]. И как одно из ее проявлений выступает «перекличка» текстов литературного произведения и жизни писателя, которая становится материалом фильма. Обнаруженная чаще всего специалистами-филологами, а не авторами фильмов, она используется ими в качестве способов сюжетосложения, основным сюжетообразующим мотивом интересующей нас разновидности «писательских фильмов».

К их числу можно отнести, в частности, такие известные работы Елены Якович и Алексея Шишова, как «Ничто не вечно. Юрий Нагибин» (2007), «Я старым не буду. Драма Вампилова» (2008), а также такие работы Романа Либерова, как «Один день с Жорой Владимовым» (2010) и «Написано Сергеем Довлатовым» (2012). Отметим, что в двух последних отражены и «злоключения текста», потому что они являются и неотъемлемой частью «текста жизни» писателей, о которых идет речь, то же самое можно сказать и о целом ряде документальных телефильмов о Михаиле Булгакове.

«Булгаковские» фильмы стоит рассмотреть с особым вниманием, поскольку здесь представляется редкая возможность сравнить в избранном аспекте несколько экранных версий одной «переклички» текстов. Возьмем три таких авторских версии, которые выходили одна за другой в следующем по- 
рядке: «Михаил Булгаков. Романы и судьба» (2000, авторы И. Золотусский, К. Антропов), «Загадки "Мастера и Маргариты"» (2005, авторы В. Лисовский, В. Хомич, Ю. Проскурня-Завьялова), «Мистическая сила Мастера» (2011, автор С. Браверман). Центральное место будет отведено фильму 2005 г. - как наиболее разнообразному в плане реализации возможностей означенного сюжетного мотива, однако начать следует с самого раннего из списка.

«Михаил Булгаков. Романы и судьба» отличается, прежде всего, очевидным и во всех отношениях подчеркнутым авторским присутствием: известный писатель-литературовед Игорь Золотусский является сценаристом и ведущим, выступающим со своей собственной оригинальной трактовкой творчества писателя. Данное обстоятельство определяет многое, в частности принцип наррации - это чистейший монолог, никто кроме автора-филолога в фильме не только не говорит (кроме, разумеется, цитируемого Булгакова), но даже не появляется в кадре, хотя бы мельком, случайно. Избрав основной нарративной стратегией «авторскую рефлексию», И. Золотусский многое из истории писателя рассказывает, то и дело уходя в рассуждения, прямо в кадре, и иногда по 5-6 минут зритель видит только говорящего нарратора на фоне значимых для понимания булгаковских текстов мест Москвы: Новодевичьего монастыря, Воробьевых гор, квартиры на Большой Садовой.Так, об адресных параллелях он говорит, указывая на город с высоты холма: Bся московская жизнь Булгакова вмещзается в этот вид <... >. На этом пространстве, которое мы видим сейчас, завязываются основные сюжеты двух главных романов Булгакова.

Автором фильма акцентирована перекличка «текста жизни» с текстами романов и на уровне литературоведческого анализа важнейших идейнохудожественных аспектов «Белой гвардии» и «Мастера и Маргариты», в частности, оппозиции «свет - тьма» или значения мотива покоя для понимания образа Мастера. Прямо в кадре И. Золотусский рассуждает: По существу, два капитальных символа стоят в ијентре романов Булгакова и, я бы сказал, в центре его жизни - это символ света и символ покоя. Свет весьма разнообразен у Булгакова. Иногда в процессе рассуждения автор уходит за кадр и его мысли сопровождаются символическим видеорядом, например известными иллюстрациями к «Мастеру и Маргарите» Нади Рушевой: Мастер прощается с Москвой - кажется, это сам Булгаков прощзается с Москвой, да и не только с Москвой, а с Россией, потому что он эмигрирует в страну искусства, он эмигрирует в смерть...

Здесь стоит отметить, что визуального документального материала в этом неторопливом по темпоритму, с медленными панорамами и наездами фильме очень немного. Редкие фотографии дополняются выразительными рисунками Н. Рушевой и А. Кумировой, а также своего рода представлением «театра теней», когда на стены «нехорошей квартиры» проецируются рисованные силуэты Коровьева и Бегемота (что обеспечивает коннотацию авторской речи с миром «Мастера и Маргариты»). С особенным вниманием авторы подходят к визуализации собственно булгаковского текста цитат из романов, которые отмечены понятными зрителю «маркерами интертекстуальности (прямыми указаниями источника или очвидной гетерогенностью текста)» [4. C. 378]. Так, например, представленные автором фрагменты из «Белой гвар- 
дии» за кадром читает актер: Елена с колен исподлобья смотрела на зубчатый венеи с потемневшим ликом и ясными глазами, и, протягивая руки, говорила шепотом... А в кадре идут снятые с нижнего ракурса панорамы по интерьеру собора и крупные планы иконы Богоматери - как визуальная презентация «точки зрения» героини.

Что касается смысловых аспектов переклички литературных текстов с «текстом жизни» Булгакова, то И. Золотусский убедительно выявляет и четко обозначает несколько, на его взгляд, ключевых моментов, среди которых: воспитание в религиозной семье, богоискательство, артистизм натуры Булгакова, его бездетность и др. Убедительность достигается, главным образом, методами литературоведческой риторики - как на литературной экскурсии высококлассного, обладающего даром красноречия специалиста. При этом автор прямо в кадре апеллирует к зрителю, и такая вспомогательная нарративная стратегия «диалога со зрителем» позволяет поддерживать коммуникативное единство повествования: Вы посмотрите, вот Новодевичий монастырь..., Вспомните, с чего начинается роман...; Здесь, в этой квартире мне хочется рассказать телезрителю...; А вывод вы сделаете сами.

Создатели фильма «Загадки "Мастера и Маргариты"» подошли к задаче экранного воплощения сюжетного мотива перекличка художественного текста и текста жизни иначе. Используя принцип полифонической наррации, а также возможность апеллировать к только что показанной в эфире многосерийной экранизации романа, они целенаправленно сосредоточились на увлекательной, полной драматических коллизий истории создания сочинения и его коннотаций с реальностью: прототипах, топосе, сюжетных аллюзиях, мифологии, возникией вокруг романа. При этом вненаходимый автор сам говорит очень мало, но в фильме достаточно голосов, ему «помогающих»: исследователи творчества писателя М. Чудакова и А. Смелянский, лично знавшие вдову писателя Е.С. Булгакову; О. Басилашвили, сыгравший Воланда в экранизации В. Бортко, и другие актеры сериала «Мастер и Маргарита», а также известный богослов, дьякон А. Кураев. И очевидно, что только полифоническая наррация позволяла коллективному автору фильма, не обладающему авторитетом И. Золотусского, рассказать историю глубоко - с помощью высказываний признанных знатоков жизни и творчества Булгакова, стереоскопично - за счет монтажа разных точек зрения на события, зрелищно посредством интертекстуальной игры, когда в повествование включаются яркие и динамичные киноцитаты из сериала-экранизации.

Перекличка романа с биографией Булгакова обозначена уже в прологе: Олег Басилашвили, находясь на месте реального действия, в квартире писателя (она описана в «Мастере и Маргарите» как «нехорошая квартира»), начинает историю рассказом о реальном эпизоде с возгоранием примуса на кухне, будто «списанным» жизнью из рукописи Булгакова (т.е. перекличка наоборот). Это, отнюдь, не единственный пример того, как события, описанные Булгаковым в "Мастере и Маргарите», совершенно необъяснимым, фантастическим образом врывались из литературы в действительность, делает вывод рассказчик, и тем самым в фильме заявляется мотив «мистического романа», которого явно избегал в своей работе И. Золотусский, даже не упомянувший о пожаре. А в «Загадке "Мастера и Маргариты"» прочтение 
романа как мистического текста, хоть и не настойчиво, но проявляется - преимущественно в авторском тексте, а специалисты, М. Чудакова и А. Смелянский, делают акцент на рационально объяснимых параллелях с биографией. В частности, М. Чудакова, проявляющая себя в фильме особенно активно, обращает внимание на отражение личного опыта писателя в знаменитой фразе Воланда о квартирном вопросе, который «испортил москвичей», а также поясняет посмертную участь Мастера обстоятельствами «договора» писателя со Сталиным: Он не заслужил света... Я думаю, здесь Булгаков сам для себя и для понимающих читателей даёт намёк на связь со своей биографией. Он считает, что тот, кто заключил - я немножко огрубляю <..> в какой-то момент союз с Сатаной, не может заслужить света. Ни он, ни Маргарита света не заслужили. Отметим, что для зрителя последний комментарий вполне понятен, поскольку ему предшествует достаточно подробный и точный в деталях совместный рассказ Чудаковой и Смелянского о звонке Сталина и реакции растерянного Булгакова, который сам, в сущности, обрек себя на дальнейшее безмолвие. В этом смысле фильм «Загадка "Мастера и Маргариты"» перекликается, в свою очередь, с работой И. Золотусского, который, впрочем, анализирует оппозицию «свет тьма» гораздо обстоятельнее и глубже, переводя литературоведческое толкование в плоскость религиозной морали (что, кстати, в «Загадке» делает и известный неортодоксальностью своих суждений православный священнослужитель, дьякон Андрей Кураев).

Однако наиболее значительным полем для обсуждаемой нами переклички в фильме «Загадка "Мастера и Маргариты"» являются не скрытые смыслы, а конкретные герои и локация. Поискам прототипов и прототопов авторы посвятили большую часть экранного времени: устанавливаются прототипы не только главных героев (Мастер - Булгаков, Маргарита - Е.С. Булгакова и Л.Е. Белозерская), но и других персонажей, в отношении которых подобная процедура возможна без «натяжек»: Воланд, Берлиоз, Бенгальский, Семплеяров, а также реальных мест, узнаваемых по тексту романа. Так, относительно трансформации поначалу «мефистофелеподобного» образа Воланда М. Чудакова поясняет: Постепенно, когда в романе появился Мастер, а именно в 32-м году, в 31-32-м, в романе «Мастер и Маргарита» Воланд начал приобретать иные очертания. Воланд стал проецироваться Булгаковым самим на Сталина. Он шёл на эту проекцию, которая приводила в оторопь и даже в ужас практически его слушателей 39-го года. Причем это утверждение звучит после слов дьякона А. Кураева: По правде говоря, Булгаков сам называет его Сатаной, и другие персонажи тоже называют Воланда Сатаной. Поэтому я не вижу оснований идти против авторской воли. Дмитрий Сергеевич Лихачёв когда-то справедливо заметил, что роман написан так, что после его прочтения нельзя сомневаться в существовании Сатань. Однако последующие высказывания обоих специалистов и, очевидно, согласного с ними автора фильма определяют прочтение зрителем «сталинского» подтекста в образе Воланда.

Гораздо четче «эхо» реальной действительности в других случаях. О прототипе Берлиоза первым говорит исполнитель его роли в сериале «Мастер и Маргарита» А. Адабашьян: «А почему такой замечательный персонаж, как Михаил Александрович Берлиоз, погибает в самом начале романа? Ну, навер- 
ное, потому что очень уж не терпелось Булгакову расправиться с человеком, прототипом которого был его личный литературный враг - Авербах, Леопольд Авербах. Далее эту известную версию уточняет профессор Чудакова: Булгаков хотел, изображая Берлиоза своего, формируя его, я думаю, он хотел отомстить сразу всем редакторам, с которыми он сталкивался. И первым из них, я думаю, был Авербах, потому что он выступил против Булгакова один из первых, против «Роковых...», повести «Роковые яйциа. Еще проще в фильме «найден» человек, ставший прообразом лишившегося головы конферансье Варьете Бенгальского. Его сразу же представляет исполнитель роли Бегемота А. Башаров: Прототип Бенгальского - один из самых популярных конферансье в московском мюзик-холле Александр Александрович Гриль. Чуть более усложненным оказалось обнаружение прототипа разоблаченного в супружеской измене Семплеярова - вслед за предъявлением версии в авторском закадровом тексте потребовался комментарий А. Смелянского о причинах такой «мести»: То, что Енукидзе играл заметную роль в Булгаковской жизни, - один из членов правящей верхушки, это точно, потому что именно Енукидзе руководил правительственной комиссией по художественному театру, вот в чём вся история. К нему же обращались со всеми доносами, всеми письмами...

И разумеется, необходимо уточнить, что во всех случаях данной переклички присутствует и еще один «голос» - цитаты из сериала «Мастер и Маргарита», не только зрелищно представляющие соответствующее место в романе, но и объясняющие причину появления в кадре говорящих о своих героях персонажах-актерах. Игровая киноцитата может в результате взаимодействия с контекстом превратиться из иллюстрации в элемент нарративного эпизода документального фильма, что мы наблюдаем в «Загадке» неоднократно. Так, рассказывая об уже упомянутом прототипе Берлиоза, ненавистном Булгакову редакторе Леопольде Авербахе, авторы следом за фотографиями с представляющим последнего закадровом текстом: Судьба реального Авербаха сложилась ничуть не лучше, чем у литературного Берлиоза. Подобно многим борцам за торжество идей советской власти, Леопольд Леонидович был этой же властью уничтожен. Авербах попал под трамвай истории: в 30-е годы он был репрессирован и сгинул в лагерях,- дают цитату из экранизации, где Коровьев (А. Абдулов) обращается к Берлиозу: Турникет ищете, гражданин? Тогда сюда. Вот прямо, и выйдете, куда надо. С вас, конечно, за указание получить бы на четверть литра, поправиться бывщему регенту... А поскольку дальше зритель видит момент попадания несчастного под колеса трамвая, то, очевидно, это уже не просто метафора («попал под трамвай истории»), а «реальная» смерть именно Авербаха, финальное событие его истории.

Более сложный случай многократного «эха» текстов, с участием не только киноцитаты, но и евангельского текста, ретранслятором которого в фильме является персонаж-резонерер дьякон Андрей Кураев, никак не причастный к истории романа, ни о чем не повествующий, а выносящий суждения о книге Булгакова именно с точки зрения канонического Евангелия. В эпизоде с сеансом магии исполнитель роли Бегемота в экранизации Александр Башаров демонстрирует фойе бывшего московского мюзик-холла, по- 
служившего прототопом булгаковскому Варьете: Булгаков представляет Воланду и его свите возможность повидать москвичей в массе именно вот здесь, а следом вступает Андрей Кураев: Вспомним хронометраж булгаковского романа. В Великую среду накануне Пасхи Воланд появляется в Москве. Перед Пасхой он исчезает. Но самое, пожалуй, яркое действо происходит в четверг, вечером в четверг. Это сеанс магии в Варьете. Мы знаем, что этот сеанс кончился крайне печально для зрителей. Но вот просто важно знать, кто эти зрители. Это ведь не просто москвичи. Понимаете, Булгаков писал в 30-е годы для людей, которые ещчё очень живо помнили, зачастую и хранили церковные традиции, в частности черковный календарь. Так вот, Великий четверг, четверг накануне Пасхи, - это самый трагический день православного богослужебного года. Большинство из тех, кто уже не дерзал ходить в храм, всё равно всё-таки сохраняли домашнюю память о том, что это особый день, день особой скорби. И, соответственно, для того, чтобы решиться в такой вечер пойти не просто в театр, не в библиотеку, а пойти в Варьете, в развлекаловку, и при этом на сеанс магии, это нужно было быть чрезвычайно сознательным атеистом. А поскольку далее следует киноцитата из экранизации с отрыванием головы Бенгальского и последующим рассказом Башарова о том, как прототип Бенгальского конферансье мюзикхолла Александр Галь вскоре также временно «лишился головы», т.е. сошел с ума и умер, то «евангельское эхо» в словах Кураева - так же, как киноцитата, в сущности, и определяют для зрителя участь Бенгальского-Галя: для служителя Варьете в тот день ничем иным это и не могло закончиться.

Последний пример вновь заставляет нас вспомнить фильм И. Золотусского, в котором евангельский текст звучит не эхом, а в прямом цитировании. Однако заметим, что это один из немногих примеров (о других уже сказано выше) явной переклички между данными фильмами, и характерно, что в «Загадке» никак не отражен отмеченный Золотусским и очень важный для «текста жизни» М. Булгакова момент - его бездетность. В фильме 2000 г. автор прямо указывает: Все женшины в его романах бездетны: Елена бездетна, Турбина, их служанка Анюта, Аннушка, которую потом мы встретим в "Мастере и Маргарите“, которая потом прольет подсолнечное масло, на котором поскользнется Берлиоз, бездетна Маргарита, и ее служанка ${ }^{1}$. В интерпретации Золотусского бездетность - символ бесплодности самой безбожной советской жизни, на которую обречена Россия. Авторы «Загадки "Мастера и Маргариты"», опиравшиеся на научный авторитет М. Чудаковой, безусловно осведомленной о фактах, опустили этот мотив, вероятно, по причине слишком «книжного» способа его обнаружения и доказательства, предпочитая те межтекстовые параллели, которые можно показать экранными средствами, в характерной для кинотекста «системе рассказа - системе показа» [4. С. 7].

А вот автор «Мистической силы Мастера» (2011) эту важную деталь не упустил, однако сделано это без каких-либо проекций на творчество.

\footnotetext{
${ }^{1}$ В почти полностью постановочном, полном откровенных компиляций фильме «Михаил Булгаков. Проклятие мастера» (2012, ТВ-3) эти слова «цитируются» почти дословно: Бездетна Елена Турбина в романе «Белая гвардия», бездетна Маргарита, бездетна ее служанка, даже роковая Аннушка, которая разольет масло, не имеет потомства.
} 
В фильме просто зафиксирован факт биографии Булгакова, который в 1917 г., в период тяжелой наркозависимости, опасаясь патологий у ребенка, сам сделал аборт своей жене Татьяне. Передав суть ситуации, ведущий резюмирует: Тот день решил судьбу обоих. Тася навсегда останется бездетной, Булгаков - тоже. Позже он скажет: “За тебя меня Бог покарает. Эх, Тась$\kappa a$, Таська...». Таким образом, не бездетность сама по себе, а мотив мистического воздаяния за судьбу Татьяны, за эгоизм и тщеславие Михаила будет реализован в дальнейшем, когда речь пойдет о несправедливости (писатель посвятил «Белую гвардию» не помогавшей ему в работе первой, а новой, второй жене), и о тщетной надежде умирающего Булгакова на предсмертное прощение Таси (ее искали по Москве, но так и не нашли).

Стоит отметить, что и не отмеченных предшественниками параллелей текстов жизни и литературы в фильме немало: профессор Преображенский и хирург Мартынов, Аннушка, пролившая масло, и Аннушка-чума из булгаковской коммуналки, самоубийство Маяковского и «самоубийство» Булгакова. Но если все они имеют мистическую окраску, то перекличка с двумя предыдущими кинотекстами проявляется в «Мистической силе Мастера» вполне реально. Нам представляется, что автор наверняка был не только знаком, но и определенным образом «отозвался» на работы предшественников в своем фильме. Так, начинается эта экранная история Булгакова, как и в «Загадке», на Большой Садовой, 10, только не в квартире писателя, а на улице у дома. Как и в фильме 2000 г., в «Мистической силе» есть ведущий, только там им был сам автор, писатель И. Золотусский, а здесь это исполняющий роль автора известный тележурналист Сергей Медведев. Так же в фильме 2011 г. активно цитируются киноэкранизации, но поскольку замысел шире, то это не только «Мастер и Маргарита» В. Бортко (2005), но и «Морфий» А. Балабанова (2008), «Дни Турбиных» В. Басова (1976), «Бег» В. Алова и А. Наумова (1970) и «Собачье сердце» того же В. Бортко (1988). Несомненно, обилие игровых киноцитат «нарушает линеарное развитие» авторского повествования, поскольку цитируемый фрагмент «получает мотивировку, интегрирующую его в текст, вне данного текста» [5. С. 61]. И, вероятно, пытаясь избежать излишней мозаичности, автор отбирает игровые фрагменты в соответствии с содержанием рассказываемой документальной истории: например, бал у Воланда из экранизации «Мастера и Маргариты» смонтирован с хроникальными кадрами со Сталиным таким образом, что полностью визуализирует коннотацию Воланд - Сталин, которая в фильме 2005 г. дана лишь в устных высказываниях персонажей.

В отличие от предшествующих фильмов в «Мистической силе Мастера» биографический нарратив создается не только посредством речевой наррации (монофонической в первом, полифонической во втором) с иллюстративным видеорядом (фото, хроника, киноцитаты, документы), но и с помощью миметического нарративного текста - постановочных эпизодов-реконструкций. Вероятно, автор хотел найти свой вариант повествования, и для этого он прибегает к нарративной стратегии «виртуального сюжета». Будто бы, проведя 
ночь в киевском музее ${ }^{1}$, «автор» видит - вместе со зрителем - сцены из жизни Булгакова (здесь и спиритический сеанс Елены Сергеевны, и разговор Михаила с Татьяной, первой женой, и т.д.), а иногда и сам становится Булгаковым (свидание с Еленой, танец в американском посольстве). Прием, на наш взгляд, не слишком удачный, порой запутывающий зрителя: например, в эпизоде, рассказывающем об истории создания «Собачьего сердца», неожиданно возникает сцена операции собаки в современной ветклинике, тогда как все остальные интермедии стилизуются «под эпоху». Тем не менее в рамках представления «текста жизни» писателя как текста мистического, полного судьбоносных совпадений, реконструкция используется автором последовательно - как «видения» в виртуальном сюжете «ночь в музее».

Заканчивается «Мистическая сила Мастера» на Новодевичьем кладбище - как и два предыдущих фильма, но это лишь композиционное совпадение, а по смыслу это три разных финала. И. Золотусский, стоя у могилы писателя и его вдовы, говорит о христианской сущности романов Булгакова, о вере в Бога их автора; в «Загадке» точку ставит исполнительница роли Маргариты Е. Ковальчук, которая рассказывает о том, как в 1966 г. Е.С. Булгакова вручила здесь, согласно воле мужа, половину гонорара первому читателю, пришедшему сюда в день официальной публикации романа; в «Мистической силе Мастера» ведущий говорит о том, что надгробием Булгакова послужил камень с могилы Гоголя, намекая тем самым на передачу «мистической эстафеты» литературной традиции.

Подводя итог, следует сказать, что авторы рассмотренных фильмов, несомненно, приступали к работе с разной интенцией: в первом случае предпринимается попытка объяснить первопричины тесной связи жизни и литературы, во втором - показать взаимоотражение реальной жизни писателя и мира его романа, а в третьем - создать миф о непостижимости гения. В результате фильм И. Золотусского является, по сути, экранной литературоведческой интерпретацией двух главных романов М. Булгакова, в то время как два других представляют собой скорее экранные метатексты разной степени достоверности. Объединяющим все три работы началом выступает реализация «интертекстуальности как приема», а также использование в качестве главного сюжетообразующего мотива «переклички текстов» жизни и литературы, который позволяет автору фильма реализовать в его диегезисе драматургический потенциал «писательской» темы. И хотя мы проанализировали в данной статье только ряд «булгаковских» фильмов, на наш взгляд, это общее свойство экранных произведений данной тематики.

\section{Лuтература}

1. Берг М. Литературократия. М., 2000. 352 c. URL: http://www.mberg.net/uspehdba/

2. Пронин А.A. Полифония как принцип наррации в биографическом фильме-портрете // Вестн. Том. гос. ун-та. Филология. 2015, № 4 (36). С. 180-189.

3. Шкловский В.Б. Гамбургский счет. М., 1990. 153 с.

4. Интертекстуальность и фигуры интертекста в дискурсах разных типов. М., 2014. $350 \mathrm{c}$.

\footnotetext{
${ }^{1}$ Вероятно, это ироническая аллюзия к знаменитому голливудскому игровому фильму «Ночь в музее» $(2006,2009)$, где герой, ночной сторож, наблюдает «оживление» экспонатов.
} 
5. Арнольд И.В. Семантика Стилистика. Интертекстуальность: сб. ст. СПб., 1999. 444 с.

6. Хренов Н.Н. Кино: реабилитация архетипической реальности. М., 2006. 704 с.

7. Ямпольский М. Память Тиресия. Интертекстуальность и кинематограф. М., 1993. 464 с.

\section{INTERTEXTUALITY "AS A DEVICE" AND THE "ROLL-CALL OF TEXTS" IN DOCU- MENTARIES ABOUT M. BULGAKOV}

Tomsk State University Journal of Philology, 2016, 2 (40), 161-170. DOI: 10.17223/19986645/40/12

Pronin Alexander A., Saint Petersburg State University (Saint Petersburg, Russian Federation). E-mail: prozin@mail.ru

Keywords: documentary, plot, motive, intertextuality, narrative, author.

The article examines the use of intertextual connections as an artistic method of creation of the biographical narrative in the modern Russian TV documentary. The object of the research is "writer's movies" popular in Russia, and the greatest interest among the authors and the public is manifested by the prohibited books or the "hidden", not published in due time by the decision of the censorship or by the will of the writer. Most of such dramatic stories belong the literature of the Soviet period, one of the most famous is associated with the name of Mikhail Bulgakov, so the article discusses the films about his life and work: Mikhail Bulgakov. Novels and Destiny (2000), Riddles of The Master and Margarita (2005), The Mystic Force of the Master (2011). The main plot motif of the analyzed films about Mikhail Bulgakov and his works appears to be the "roll-call" of the text of a literary work and the "text of life" of the writer: at the level of images, actions, meanings and the topos. The comparison shows a variety of ways of visualising intertextual relations, their dependence on the author's intention and narrative strategies. In the first film the author, a famous writer Igor Zolotussky, speaks with a religious and philosophical interpretation of the creativity of the writer. He analyzes the roll-call of the "text of life" and the texts of the novels at the level of important ideological-artistic aspects of The White Guard and The Master and Margarita, in particular, of the opposition "light-dark" or the significance of the motif of rest for a better understanding of the Master. With the help of quotations, Zolotussky also convincingly identifies and clearly outlines a few key points of Bulgakov's life reflected in the novels: upbringing in a religious family, God, the artistic nature of Bulgakov, his childlessness, etc. It is achieved by methods of literary rhetoric, citing and concise visualization (landscape, figures, photographs). The authors of Riddles of The Master and Margarita came to the task of the onscreen incarnation of the plot motif of the "roll-call" of the artistic text and the "text of life" differently. Using the principle of a polyphonic narration, as well as the opportunity to appeal to the TVbased version of the novel, they purposefully focused on the exciting, full of dramatic conflicts history of the work and its connotations with the reality: prototypes, topos, plot, allusions, mythology that appeared around the novel. In the film The Mystic Force of the Master, the authors present the "text of life" of the writer as a text full of fateful coincidences, and to implement this plan they use not only film quotations, but also artistic reconstruction - like a vision in the virtual plot "Night at the Museum". In the end, the article concludes that the motif of the "roll-call of texts" in the first film is used to explain the root causes of the close relationship of life and literature, in the second to demonstrate the interaction of the writer's real life and the world of his novel, and the third to creation a myth about the incomprehensibility of a genius.

\section{References}

1. Berg, M. (2000) Literaturokratiya [Literaturecracy]. [Online]. Avalable from: http://www. mberg.net/uspehdba/.

2. Pronin, A.A. (2015) Polyphony as the principle of narration in the biopic-portrait. Vestnik Tomskogo gosudarstvennogo universiteta. Filologiya - Tomsk State University Journal of Philology. 4 (36). pp. 180-189. (In Russian).

3. Shklovskiy, V.B. (1990) Gamburgskiy schet [The Hamburg score]. Moscow: Sovetskiy pisatel'.

4. Kolokol'tseva, T.N. \& Moskvin, V.P. (eds) (2014) Intertekstual'nost' $i$ figury interteksta $v$ diskursakh raznykh tipov [Intertextuality and intertext figures in discourses of different types]. Moscow: Flinta: Nauka.

5. Arnol'd, I.V. (1999) Semantika. Stilistika. Intertekstual'nost' [Semantics. Stylistics. Intertextuality]. St. Petersburg: St. Petersburg State University.

6. Khrenov, N.N. (2006) Kino: reabilitatsiya arkhetipicheskoy real'nosti [A Film: rehabilitation of archetypal reality]. Moscow: Agraf.

7. Yampol'skiy, M. (1993) Pamyat' Tiresiya. Intertekstual'nost' $i$ kinematograf [Memory of Tiresias. Intertextuality and cinema]. Moscow: Ad Marginem. 